\title{
Assessment of wound area reduction on chronic wounds in dogs with photobiomodulation therapy: A randomized controlled clinical trial
}

\author{
Somphong Hoisang1(D), Naruepon Kampa² (D), Suvaluk Seesupa² ${ }^{2}$ and Supranee Jitpean² (D) \\ 1. Veterinary Teaching Hospital, Faculty of Veterinary Medicine, Khon Kaen University, Khon Kaen, Thailand; 2. Division \\ of Surgery, Faculty of Veterinary Medicine, Khon Kaen University, Khon Kaen, Thailand. \\ Corresponding author: Supranee Jitpean, e-mail: supraneeji@kku.ac.th \\ Co-authors: SH: sompho@kku.ac.th, NK: naruepon@kku.ac.th, SS: suvalukse@kku.ac.th \\ Received: 22-04-2021, Accepted: 28-07-2021, Published online: 28-08-2021
}

doi: www.doi.org/10.14202/vetworld.2021.2251-2259 How to cite this article: Hoisang S, Kampa N, Seesupa S, Jitpean S (2021) Assessment of wound area reduction on chronic wounds in dogs with photobiomodulation therapy: A randomized controlled clinical trial, Veterinary World, 14(8): 2251-2259.

\begin{abstract}
Background and Aim: Chronic wounds are a clinical problem and require intensive standard wound care. However, this is sometimes insufficient to promote healing. Photobiomodulation therapy (PBMT) can be used as an adjunctive therapy to improve wound healing. Various PBMT devices with different properties and parameter settings as well as different animal species can influence a variety of clinical outcomes. This study aims to assess the use of $830 \mathrm{~nm}$ PBMT or simultaneous superpulsed and multiple wavelengths (SPMW; 660, 875, and $905 \mathrm{~nm}$ ) PBMT on chronic wounds in client-owned dogs.

Materials and Methods: This study included 21 client-owned dogs with chronic wounds allocated into three groups: (1) Control group (C) treated with irrigated saline and without PBMT (n=7); (2) L1 group treated with irrigated saline together with the radiation of $830 \mathrm{~nm}$ PBMT ( $\mathrm{n}=7$ ); and (3) L2 group treated with irrigated saline together with the radiation of simultaneous SPMW-PBMT $(n=7)$. Wound healing was assessed on the basis of wound size reduction as a percentage of wound area every $2^{\text {nd }}$ day for 15 days using image analysis software (Image J software ${ }^{\circledR}$, National Institutes of Health, Rockville, Maryland, USA).

Results: A significant difference in the percentage of wound area reduction was noted between the C and PBMT groups (L1 and L2; $<0.05$ ). The average percentages of wound area reduction at the end of the study (15 days) were $42.39 \pm 20.58$, $56.98 \pm 24.82$, and $61.81 \pm 27.18$ in the C, L1, and L2 groups, respectively. A steady decrease in wound size was noted in both PBMT and non-PBMT groups, and coefficients were 7.77, 8.95, and 10.01 in the C, L1, and L2 groups, respectively. The percentage of wound area reduction was found to be significantly different between the PBMT and non-BPMT groups on day $7(\mathrm{p}<0.05)$.

Conclusion: Based on the results of the current study, using either $830 \mathrm{~nm}$ PBMT or simultaneous SPMW-PBMT can accelerate the chronic wound healing process in dogs with a significant reduction in wound area. Therefore, it can be used as an adjunctive therapy to improve wound healing in dogs with reduced treatment duration.
\end{abstract}

Keywords: canine, chronic wound, combined wavelength photobiomodulation therapy, low-intensity laser therapy, photobiomodulation therapy.

\section{Introduction}

A chronic wound is defined as a wound that fails to heal over 3 weeks with standard wound care $[1,2]$. Moreover, chronic wounds require intensive standard wound care; however, this is sometimes insufficient to promote healing. At present, photobiomodulation therapy (PBMT) can be used as adjunctive therapy for improving wound healing in veterinary medicine $[3,4]$, dentistry [5], and medicine [6,7]. PBMT involves the use of therapeutic light, including laser, light-emitting diode, and broadband light, in the visible and infrared spectrum [8]. The photobiomodulation process is well understood where it can stimulate

Copyright: Hoisang, et al. Open Access. This article is distributed under the terms of the Creative Commons Attribution 4.0 International License (http://creativecommons.org/licenses/ by/4.0/), which permits unrestricted use, distribution, and reproduction in any medium, provided you give appropriate credit to the original author(s) and the source, provide a link to the Creative Commons license, and indicate if changes were made. The Creative Commons Public Domain Dedication waiver (http:// creativecommons.org/publicdomain/zero/1.0/) applies to the data made available in this article, unless otherwise stated. endogenous chromophores in mitochondrial membranes and produce cellular adenosine triphosphate, which is a universal fuel inside living cells [9]. It stimulates the mitochondrial membrane potential, leading to the release of nitric oxide, and modulates reactive oxygen species as a photochemical reaction, which drives all biological reactions and improves cellular metabolism [10]. PBMT has been reported to influence various phases of wound healing $[11,12]$, including increased endothelial cells and keratinocyte proliferation, fibroblast proliferation, collagen deposition, angiogenesis, granulation tissue formation, and improvement of wound tensile strength $[13,14]$.

A few clinical studies in veterinary medicine have been conducted to evaluate the use of PBMT on open wounds and had various outcomes. The PBMT using a $632.8 \mathrm{~nm}$ wavelength with a fluence of $2.64-3.64 \mathrm{~J} / \mathrm{cm}^{2}$ accelerated wound healing by increasing epithelialization in dairy cattle [15]. The use of a $635 \mathrm{~nm}$ wavelength with a fluence of $5.1 \mathrm{~J} / \mathrm{cm}^{2}$ gave significantly faster equine wound healing from the epithelialization 
result [4]. Recently, applying a simultaneous combination of 850 and $670 \mathrm{~nm}$ wavelengths with a fluence of $8 \mathrm{~J} / \mathrm{cm}^{2}$ significantly improved the clinical scar scale in patients with thoracolumbar hemilaminectomy [16]. However, several PBMT parameters had no beneficial effects on wound healing. PBMT using 635 and $980 \mathrm{~nm}$ wavelength with a fluence of 1.125 [17] and $5 \mathrm{~J} / \mathrm{cm}^{2}$ [18] did not enhance wound healing of canine incised wound healing by complete granulation tissue formation and epithelialization.

Simultaneous superpulsed and multiple wavelengths (SPMW)-PBMT equipment provides red light $(660 \mathrm{~nm})$, broadband light $(875 \mathrm{~nm})$, and superpulsed light $(905 \mathrm{~nm})[19,20]$, providing a higher peak power and more beneficial effects into the target tissue without thermal effects [21,22]. However, information on simultaneous SPMW-PBMT application as an alternative treatment for wounds in small animals is limited.

This study aims to evaluate the clinical outcome of a single wavelength of $830 \mathrm{~nm}$ PBMT, simultaneous SPMW-PBMT $(660,875$, and $905 \mathrm{~nm})$, and without PBMT on chronic wounds in client-owned dogs. The hypothesis was that a chronic wound treated with PBMT can heal faster without PBMT as assessed by wound area reduction.

\section{Materials and Methods}

\section{Ethical approval and Informed consent}

This study was a randomized controlled clinical trial and was approved by the Institutional Animals Care and Use Committee of Khon Kaen University (IACUC-KKU 17/61). The owners allowed their dogs to participate and signed the consent form before study commencement.

\section{Study period and location}

This study was conducted from May 2018 to July 2020. All procedures were performed at Veterinary Teaching Hospital (VTH), Khon Kaen University, Thailand.

\section{Samples}

The sample size of the study was calculated based on a study of wound healing comparison using a superiority trial (two-sample parallel design for continuous data) [23]. The effect on the size of wound healing between groups was 7.11, and the standard deviation was 4.94 , in combination with a specified significance level of 0.05 and beta probability of 0.2 [24]. Client-owned dogs presented at VTH, Khon Kaen University with a chronic wound that failed to heal after 3 weeks of wound age and had a wound area of at least $4 \mathrm{~cm}^{2}$ were recruited into the study. The treatment cost of enrolled dogs was provided from the research fund during the study or the wound was completely healed (2-4 weeks). The dogs were considered healthy based on general physical examinations, complete blood counts, and serum biochemistry analyses. The inclusion/exclusion criteria of the current study are shown in Table-1.
Table-1: Inclusion/exclusion criteria of the study.

\begin{tabular}{|c|c|}
\hline Inclusion criteria & Exclusion criteria \\
\hline $\begin{array}{l}\text { Chronic wound over } 3 \\
\text { weeks }\end{array}$ & $\begin{array}{l}\text { Presence of wound exudate/ } \\
\text { discharge }\end{array}$ \\
\hline $\begin{array}{l}\text { ickness open wound } \\
4 \mathrm{~cm}^{2} \text { from any }\end{array}$ & g conditions: \\
\hline & \\
\hline gical wound & \\
\hline $\mathrm{Ba}$ & $\mathrm{hC}$ \\
\hline $\begin{array}{l}<1 \\
\text { wi }\end{array}$ & $\begin{array}{l}\text { ev } \\
\text { pla }\end{array}$ \\
\hline Availability of written & sibility of wound cover \\
\hline
\end{tabular}

PBMT=Photobiomodulation therapy

In this study, all dogs with wounds were initially treated with standard wound care with the same course of antibiotics and analgesics (cephalexin, $22-30 \mathrm{mg} / \mathrm{kg}$ twice daily; tramadol hydrochloride, $3-4 \mathrm{mg} / \mathrm{kg}$ twice daily; topical nitrofural [Bactacin ${ }^{\circledR}$, Osoth Inter Laboratories, Thailand]). Susceptibility antibiotics were used as needed until signs of wound infection were no longer noted. Dogs with wounds for more than 3 weeks after treatment and without purulent wound discharge or signs of wound infections based on the bacterial culture were considered to be delayed wound healing subjects and were enrolled in this study. Twenty-four dogs met the inclusion criteria. However, three dogs were excluded from the study: The first, second, and third cases presented neurological signs on day 9 of the study, lost contact on day 3 of treatment, and presented with anemia and blood parasite infection, respectively. Therefore, 21 dogs were used in the study (12 male and 9 female dogs; average, 5.3 years [range, 1-12 years old]). The average wound age was 3.9 weeks (range, $3-11$ weeks). The wounds were caused by a bite $(47.62 \%)$, vehicular accident trauma $(23.81 \%)$, and surgical wound dehiscence $(28.57 \%)$.

\section{Treatments}

The selected cases were randomly allocated into three groups using the Microsoft Excel program: Control group (C; non-PBMT) treated with irrigated saline and without PBMT, L1 group treated with irrigated saline together with the radiation of $830 \mathrm{~nm}$ PBMT, and the L2 group treated with irrigated saline together with the radiation of simultaneous SPMWPBMT. The wounds in the $\mathrm{C}$ group were treated with irrigated saline without topical medication every $2^{\text {nd }}$ day for 2 weeks. The two PBMT groups (L1 and L2) were treated with irrigated saline without topical medication together with the different PBMTs every $2^{\text {nd }}$ day for 2 weeks (Table-2). The wound in the L1 group was radiated with a single wavelength of $830 \mathrm{~nm}$ PBMT (BTL-5800 SL Combi, BTL Industries Ltd., London, UK) with the dose setting recommended by Millis and Saunders [25] and based on our previous study [26]. The wound in the L2 group was 
Table-2: Treatment protocol and PBMT parameter.

\begin{tabular}{|c|c|c|c|}
\hline Group & Treatment protocol & PBMT parameter & PBMT equipment \\
\hline $\mathrm{C}$ & $\begin{array}{l}\text { Irrigated saline } \\
\text { lavage without topical } \\
\text { medication }\end{array}$ & - & - \\
\hline L1 & $\begin{array}{l}\text { Irrigated saline } \\
\text { lavage without topical } \\
\text { medication + PBMT }\end{array}$ & $\begin{array}{l}830 \mathrm{~nm} \text { wavelength with fluence of } 4 \mathrm{~J} / \mathrm{cm}^{2} \text {, power of } 200 \mathrm{~mW} \text {, } \\
\text { and frequency of } 50 \mathrm{~Hz} \text {; time of treatment was calculated from } \\
\text { the wound area which is between } 3.45 \text { and } 41.40 \mathrm{~min}\end{array}$ & $\begin{array}{l}\text { BTL-5800 SL Combi, BTL } \\
\text { Industries Ltd., UK }\end{array}$ \\
\hline L2 & $\begin{array}{l}\text { Irrigated saline } \\
\text { lavage without topical } \\
\text { medication + PBMT }\end{array}$ & $\begin{array}{l}\text { Synchronous use of light power of SPMW ( } 100 \mathrm{~mW} \text { of } \\
660 \mathrm{~nm} ; 250 \mathrm{~mW} \text { of } 875 \mathrm{~nm} \text {; peak pulse power } 50 \mathrm{~W} \text { [pulse } \\
\text { duration of } 110 \pm 20 \mathrm{~s} \text { ] of } 905 \mathrm{~nm} \text { ), time of treatment used } \\
\text { was } 1 \mathrm{~min} / 4 \mathrm{~cm}^{2} \text { of wound area which is between } 1 \text { and } 5 \text { min }\end{array}$ & $\begin{array}{l}\text { MR4 ActiVet Pro, Multi } \\
\text { Radiance Medical }{ }^{\circledR} \text {, USA }\end{array}$ \\
\hline
\end{tabular}

PBMT=Photobiomodulation therapy. C: Control group; L1: Adjunctive therapy with the $830 \mathrm{~nm}$ wavelength PBMT (BTL5800 SL Combi); L2: Adjunctive therapy with superpulsed multiple wavelength PBMT (MR4 ActiVet Pro Veterinary Laser)

radiated with simultaneous SPMW-PBMT $(660,875$, and $905 \mathrm{~nm}$; MR4 ActiVet Pro Veterinary Laser, Multi Radiance Medical, Solon, OH, USA) with a preset program for tissue repairing protocol from the manufacturer's recommendations. The PBMT device probe was used with a noncontact technique (1-cm distance wound probe) and was irradiated covering the entire wound with a $0.5-\mathrm{cm}$ margin surrounding the wound. Sedation in any of the dogs was not required for wound care. The wound was covered by a sterile gauze pad and changed every $2^{\text {nd }}$ day. All procedures for each dog were performed by one observer $(\mathrm{SH})$.

\section{Wound healing measurement}

Wound healing was assessed by the change of wound size obtained from a wound photograph that was adapted from the Bates-Jensen Wound Assessment [27]. The wounds were photographed using a 12-megapixel digital camera (Olympus E-PM1 with 14-42 II lens, Japan) with a calibrated scale beside the wound edge and inside the photo frame. Photographs were taken perpendicular to the wound and approximately $15 \mathrm{~cm}$ from the wound on days $1,3,5,7,9,11,13$, and 15 by the same observer (SH). The wound area was calculated by ImageJ software $^{\circledR}$ (National Institutes of Health, USA) $[12,17,28]$. The wound area on the initial day of treatment was considered as $100 \%$. The change of wound size was compared with that of day 1 and was reported as the percentage of wound area reduction. The percentage of wound area reduction was calculated using the previously published formula [29-31]:

$\%$ wound area $=[(\mathrm{W} 1-\mathrm{Wx}) / \mathrm{W} 1] \times 100$

$\mathrm{W} 1=$ the initial wound area

$\mathrm{Wx}=$ the area on measurement day.

\section{Statistical analysis}

The $\mathrm{C}$ and experimental (L1 and L2) groups were statistically analyzed by a repeated linear mixed model (two levels) to find the average wound area reduction evaluation. The full model included fixed effects as a treatment protocol, healing day evaluation, and their interaction effect. A random slope was a subject's (dog's) response as wound healing evaluation measured on several time points with a covariance structure (unstructured). Statistical analysis was performed using commercially available software, STATA version 10.1 (StataCorp LLC, USA). The level of significance was considered as $p<0.05$.

\section{Results}

A significant difference in wound size between groups with an average of $21.7 \mathrm{~cm}^{2}(\mathrm{p}<0.05$; range, 4.0-104.6 $\mathrm{cm}^{2}$ ) was noted before treatment (Table-3). Therefore, the wound area was adjusted as the percentage of wound area reduction at baseline before data analyses. A steady decrease in wound size was noted in both PBMT and non-PBMT groups (Figure-1). The change in wound size (percentage of wound area reduction) significantly increased over time with the coefficients 7.77, 8.95, and 10.01 for $\mathrm{C}, \mathrm{L} 1$, and L2, respectively (Figure-2). However, the percentage of wound area reduction was found to be significantly different between PBMT and non-BPMT groups on day $7(\mathrm{p}<0.05)$. At the end of the study (day 15), the wounds of the two cases in the L2 group were completely healed. Overall, a significant difference in the percentage of wound area reduction was noted between the C and PBMT groups (L1 and L2; $\mathrm{p}<0.05$ ). The average percentages of wound area reduction were $42.39 \pm 20.58,56.98 \pm 24.82$, and $61.81 \pm 27.18$ in C, L1, and L2, respectively (Table-4).

\section{Discussion}

The current study indicated that PBMT can accelerate wound healing assessed on the basis of wound area reduction. The wounds in this study were treated with PBMT as an adjunctive therapy. Moreover, treatment with a single wavelength of $830 \mathrm{~nm}$ PBMT with a fluence of $4 \mathrm{~J} / \mathrm{cm}^{2}$, power of $200 \mathrm{~mW}$, and frequency of $50 \mathrm{~Hz}$, and simultaneous SPMW-PBMT with a preset of $1-250 \mathrm{~Hz}$ showed significant improvement of the wound healing process on the basis of wound size reduction compared with a non-PBMT treatment from days 7 to 13 after treatment. This finding supports a previous PBMT parameter study using an $830 \mathrm{~nm}$ light with a dose of $4 \mathrm{~J} / \mathrm{cm}^{2}$ that would be appropriate for superficial wound treatment in dogs [26]. In addition, our result is related to the findings of the previous studies, which noted an improvement in mice wound healing with the use of a single $830 \mathrm{~nm}$ 


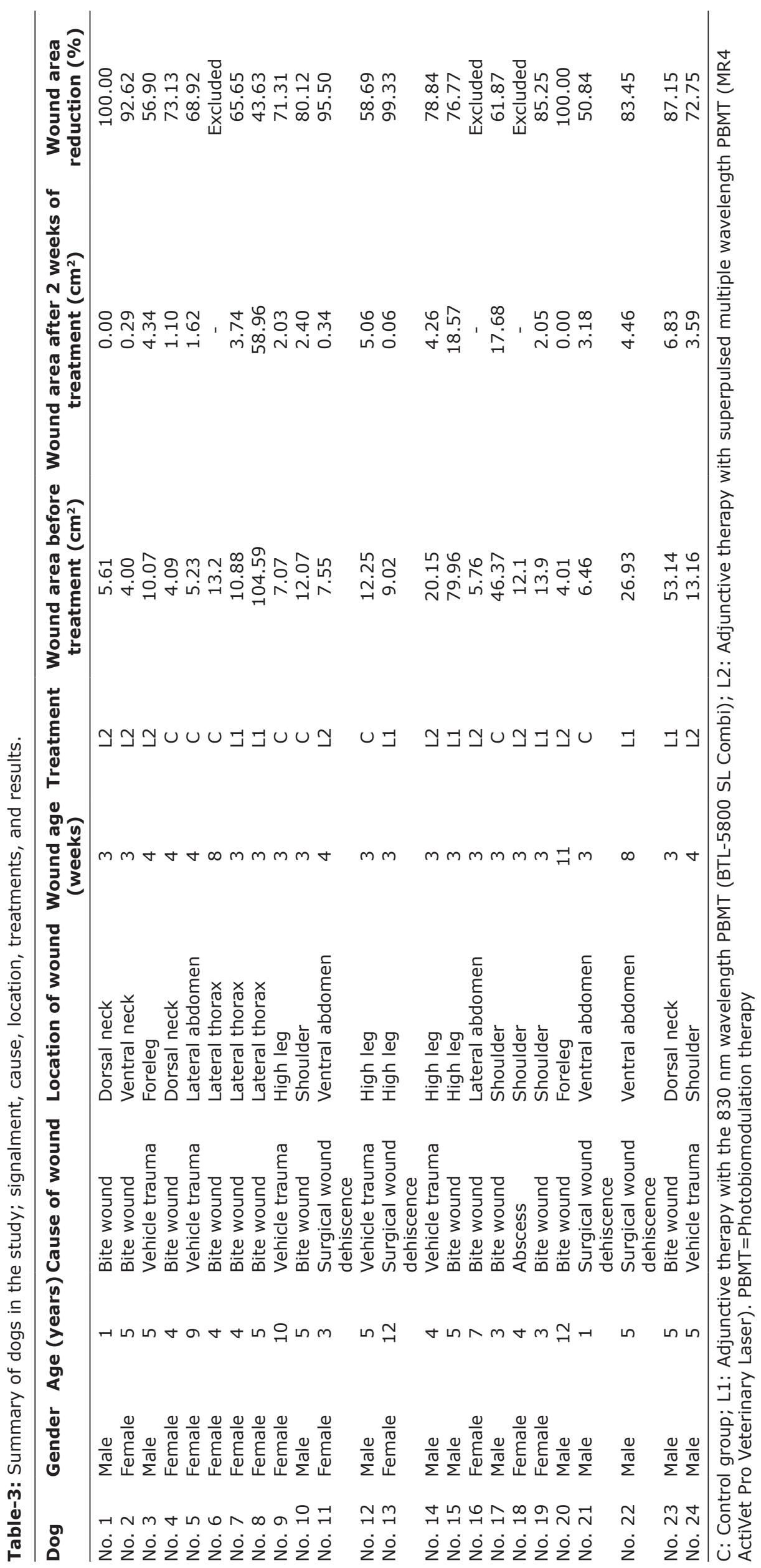



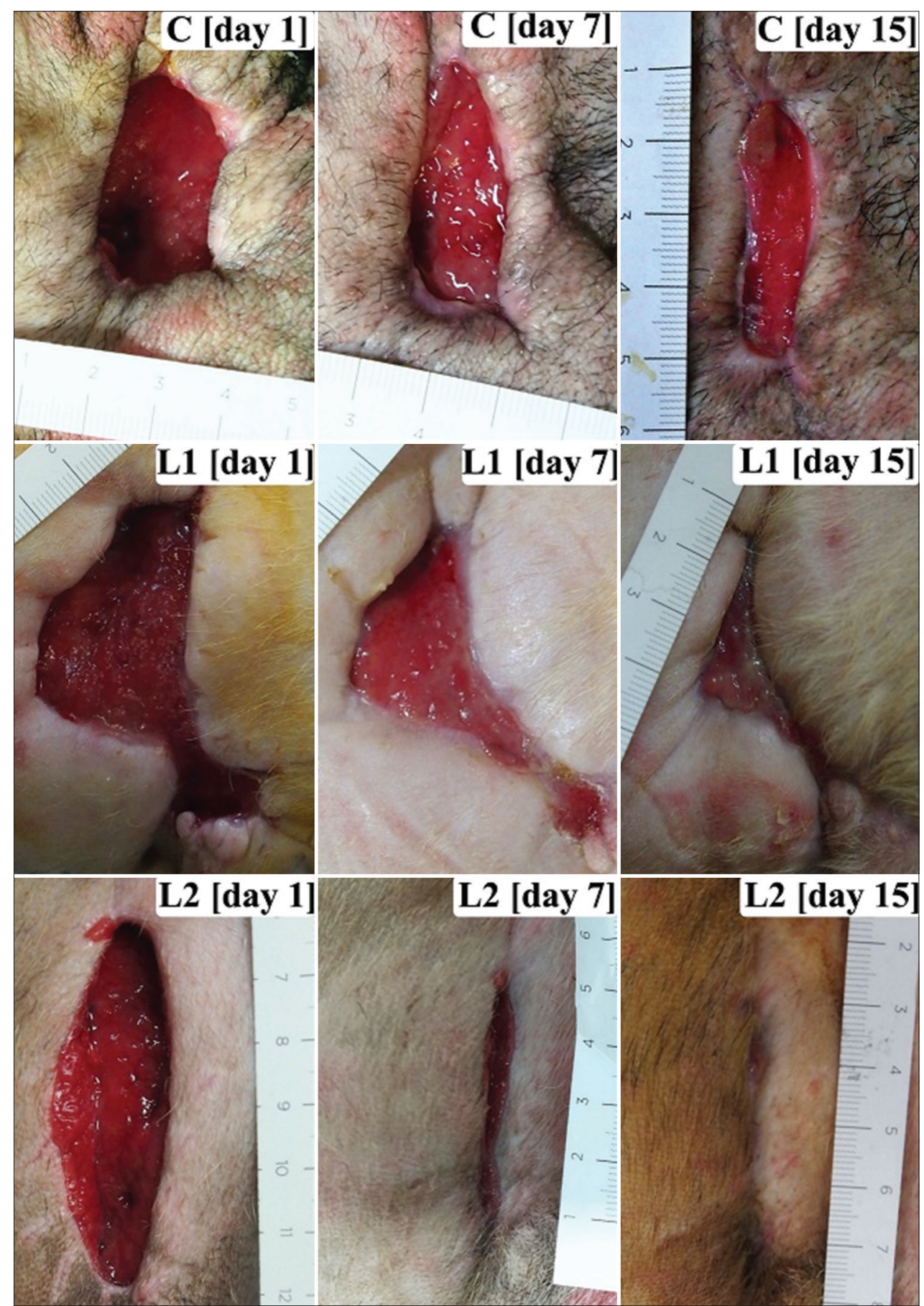

Figure-1: Wound photographs showing the variety of the initial wound area of clinical cases. The percentages of wound area reduction of photobiomodulation therapy (PBMT) groups (L1 and L2) were significantly higher than the non-PBMT group (C) from days 7 to 13 after beginning the treatment $(p<0.05)$.

PBMT with a fluence of $3-4.2 \mathrm{~J} / \mathrm{cm}^{2}$ [32,33]. In clinical case reports, human venous ulceration wounds treated with $830 \mathrm{~nm}$ PBMT with a dose of $9 \mathrm{~J} / \mathrm{cm}^{2}$ [34] and chronic dog wounds treated with the use of a single $630 \mathrm{~nm}$ wavelength PMBT with a fluence of $5 \mathrm{~J} / \mathrm{cm}^{2}[28]$ exhibited more rapid wound area reduction. This potentially confirms in vitro studies showing that PBMT improved biological immune response by increasing the migration of primary cytokines (interleukin-1 $\beta$ [IL-1 $\beta]$, tumor necrosis factor- $\alpha$, IL-6, and MCP-1) [35], neutrophil and macrophage infiltration [36], angiogenesis, fibroblast and collagen formation, reepithelialization, and wound tensile strength [37-39].

At present, evidence of the use of simultaneous SPMW-PBMT on wound healing in dogs is limited. Comparing the studies with different PBMT devices and parameter settings are difficult. One study investigated the effect of simultaneous SPMW-PBMT at a preset of $5 \mathrm{~Hz}$ and found no apparent improvement on surgically induced full-thickness wounds in amphibians [19]. Applying a combination of $637\left(0.2 \mathrm{~J} / \mathrm{cm}^{2}\right)$ and $956\left(1.2 \mathrm{~J} / \mathrm{cm}^{2}\right) \mathrm{nm}$, PBMT presented no significant decrease in wound size in equine wounds [40]. 


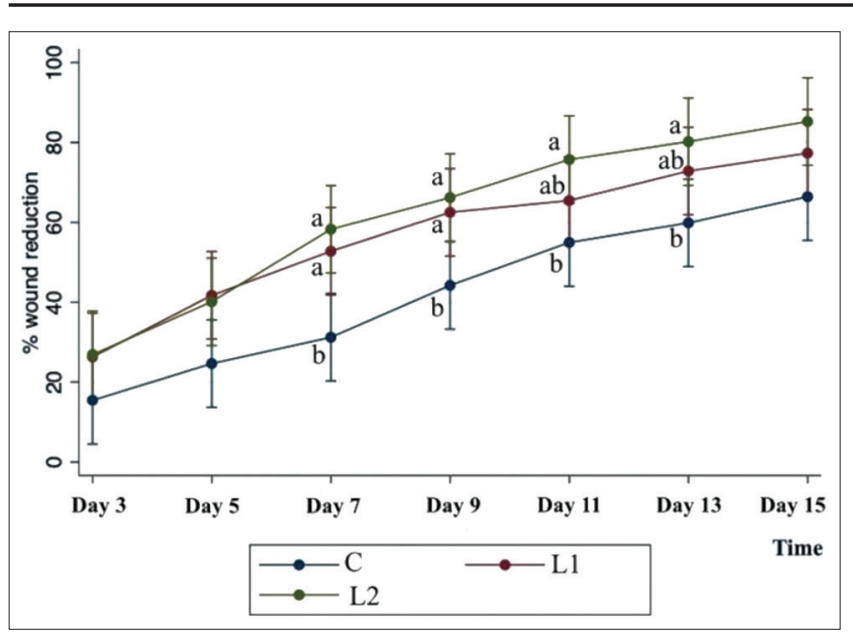

Figure-2: A linear graph of percentage of wound reduction with time, showing a significant increase over time (a lower-case letter indicates a significant difference, $\mathrm{p}<0.05)$, the coefficients were $7.77,8.95$, and 10.01 in $C, L 1$, and $L 2$, respectively. In addition, the wound treated with simultaneous superpulsed and multiple wavelengthsphotobiomodulation therapy (SPMW-PBMT) was observed to have a tendency to be better than the $830 \mathrm{~nm}$ PBMT group and control in the reduction of wound size ( $\mathrm{C}$ : Control group; L1: Adjunctive therapy with the $830 \mathrm{~nm}$ wavelength PBMT; and L2: Adjunctive therapy with simultaneous SPMW-PBMT).

However, several studies were impressed with the outcome of the combination of wavelength PBMT. A combination of 660 and $890 \mathrm{~nm}$ PBMT at a dose of $3 \mathrm{~J} / \mathrm{cm}^{2}$ can accelerate diabetes leg ulcer wound healing in humans [41]. Similarly, clinical use of 850 and $670 \mathrm{~nm}$ and a dose of $8 \mathrm{~J} / \mathrm{cm}^{2}$ showed significantly improved cosmetic healing of incised wounds in dogs [16].

Interestingly in this study, no statistical difference $(p=0.85)$ was noted when comparing the L1 and L2 groups, although the wounds treated with simultaneous SPMW-PBMT were observed to tend to be better than the $830 \mathrm{~nm}$ PBMT-treated group in wound size reduction (Figure-2). A further study needs to be done to confirm this finding. Several studies of potential applications in vitro have been done, demonstrating that the use of combined PBMT showed evidence of new blood vessel formation, intense inflammatory reaction, collagen matrix formation, and reepithelization [38,42-44]. Radiation at different wavelengths would affect different target tissues, and the tissue could absorb different amounts of radiation [45]. A synergistic effect based on a combination of red light, infrared, and superpulsed technology may occur in target cells and tissue surrounding those cells directly irradiated [7]. Recent in vivo studies of superpulsed light showed a deeper penetration in human [46] and horse tissues [20]. Therefore, the application of simultaneous SPMW-PBMT for the treatment of deep tissue conditions may give better outcomes. Moreover, the advantage of a simultaneous SPMW-PBMT device is the probe, which is designed as a shower probe for delivering synchronous multiple 
therapeutic light sources. This type of probe would provide more power and reduce treatment time.

Despite the results of the current study confirming that the use of both PBMTs showed positive results on chronic wound healing, several studies have shown no significant difference of PBMT on the healing of surgically created wound in dogs $[17,18]$. The difference in these results may be caused by inappropriate PBMT parameter settings and may not be suitable for specific species. The published dose in vitro or in vivo of other species may not be suitable for use in canine skin wound models due to the different properties of the skin and the healing process in different species [47]. It is believed that the PBMT dose recommendation for an open wound is suggested to be 2-8 $\mathrm{J} / \mathrm{cm}^{2}$ [25]. However, the use of combination wavelength PBMTs has no dose setting recommendation. Therefore, the simultaneous SPMW-PBMT dosage of this study was set based on the manufacturer's recommendations for wound healing purposes at $1-250 \mathrm{~Hz}$.

Assessment of wound healing in this study was based on the macroscopic changes from a digital photograph and analyzed using image analysis software (ImageJ software ${ }^{\circledR}$ ) as mentioned earlier, which is widely utilized in research and provides accuracy for patient monitoring in clinical practice [48]. The photographic method is accepted as an appropriate technique for measuring wound area in clinical studies without contact with the wound bed [49] and does not require histopathologic confirmation in client-owned animals $[16,28,40]$. The result of the current study showed a significant difference between the nonPBMT and PBMT groups from days 7 to $13(\mathrm{p}<0.05)$. At the end of the study (day 15), two cases in the L2 group had complete wound healing. This may influence the reduction rate of the wound size in the PBMT group and may result in a non-significant difference in the wound size between groups on day $15(p=0.06)$.

The limitations of this study include the number of clinical cases that met the criteria and the consequent implications for the statistical power between distinct PBMT groups. This study was done on clinical cases, and the wound size at study commencement could not be controlled. Therefore, the wound size at the beginning of the study showed a statistical difference between dogs $(p=0.03)$. The wound size needed to be adjusted because the percentage of wound area reduction inherently controls for different wound sizes at baseline before data analysis. In addition, the participants were considered healthy by general physical examination and blood profiles. Moreover, no significant differences in age $(p=0.94)$, gender $(\mathrm{p}=0.47)$, and cause of wound $(\mathrm{p}=0.41)$ were noted. However, the variation in the individual cases may influence the wound healing process. Another limitation was the absence of histopathological results because they could not be done on the client-owned dogs. Moreover, information would be gathered if histopathological analyses were performed. Therefore, the inflammatory cell infiltration, new blood vessel formation, fibroblast formation, collagen formation, and epithelialization could not be evaluated. The possible limitation of the $830 \mathrm{~nm}$ PBMT is the size of the convergent probe having a small aperture of $1 \mathrm{~cm}^{2}$, which takes more time in treating a larger wound area. Moreover, simultaneous SPMW-PBMT is designed as a cluster probe with an aperture of $4 \mathrm{~cm}^{2}$, which is used for a larger treatment area, and would increase the risk of eye injuries from an incidence of reflected light. Further studies may be conducted on the potential of PBMT for wound healing in other species (e.g., cats) with different skin vascularity and healing properties. In addition, a clinical investigation into the effects of PBMT or combined blue light and PBMT on infected wounds is needed.

\section{Conclusion}

The use of a single wavelength of $830 \mathrm{~nm}$ PBMT with a fluence of $4 \mathrm{~J} / \mathrm{cm}^{2}$, power of $200 \mathrm{~mW}$, and frequency of $50 \mathrm{~Hz}$ or simultaneous SPMW-PBMT (660, 875 , and $905 \mathrm{~nm}$ ) with a preset of $1-250 \mathrm{~Hz}$ resulted in a significant reduction in the wound area in the client-owned dogs. Therefore, PBMT could be used as an adjunctive therapy to reduce treatment duration and improve the quality of life. Further studies need to be performed to validate this result in clinical practice.

\section{Authors' Contributions}

NK and SJ: Designed and supervised the study. $\mathrm{SH}$ : Conducted the literature search and performed the experiments. SS: Performed the data analysis. NK, SJ, and SH: Wrote the manuscript. All authors read, revised, and approved the final manuscript.

\section{Acknowledgments}

This study was funded by the Faculty of Veterinary Medicine, Khon Kaen University, Thailand (Grant number: VM2561.5). The authors would like to thank Sajee Sattayut (DDS, Ph.D.) and the Laser in Dentistry Research Group, Khon Kaen University, for advice on the general concept of PBMT. The authors wish to acknowledge Ian Thomas (M.Sc.) for linguistic revision.

\section{Competing Interests}

The authors declare that they have no competing interests.

\section{Publisher's Note}

Veterinary World remains neutral with regard to jurisdictional claims in published and institutional affiliation.

\section{References}

1. Olsson, M., Jarbrink, K., Divakar, U., Bajpai, R., Upton, Z., Schmidtchen, A. and Car, J. (2019) The humanistic and economic burden of chronic wounds: A systematic review. Wound Rep. Reg., 27(1): 114-125.

2. Swanson, E.A., Freeman, L.J., Seleem, M.N. and Snyder, P.W. (2014) Biofilm-infected wounds in a dog. 
J. Am. Vet. Med. A., 244(6): 699-707.

3. Bruno, E., Canal, S., Antonucci, M., Bernardini, M., Balducci, F., Musella, V., Mussoni, M. and Spinella, G. (2020) Perilesional photobiomodulation therapy and physical rehabilitation in post-operative recovery of dogs surgically treated for thoracolumbar disk extrusion. BMC Vet. Res., 16(1): 120.

4. Jann, H.W., Bartels, K., Ritchey, J.W., Payton, M. and Bennett, J.M. (2012) Equine wound healing: Influence of low level laser therapy on an equine metacarpal wound healing model. Photonics. Lasers Med., 1(2): 117-122.

5. Scarano, A., Lorusso, F., Postiglione, F., Mastrangelo, F. and Petrini, M. (2021) Photobiomodulation enhances the healing of postextraction alveolar sockets: A randomized clinical trial with histomorphometric analysis and immunohistochemistry. J. Oral Maxillofac. Surg., 79(1): e1.1-e1.12.

6. Feitosa, M.C.P., Carvalho, A.F.M., Feitosa, V.C., Coelho, I.M., Oliveira, R.A. and Arisawa, E.A.L. (2015) Effects of the low-level laser therapy (LLLT) in the process of healing diabetic foot ulcers. Acta. Cir. Bras., 30(12): 852-857.

7. Hopkins, J.T., McLoda, T.A., Seegmiller, J.G. and Baxter, G.D. (2004) Low-level laser therapy facilitates superficial wound healing in humans: A triple-blind, sham-controlled study. J. Athl. Train., 39(3): 223-229.

8. Anders, J.J., Ketz, A.K. and Wu, X. (2017) Basic principles of photobiomodulation and its effects at the cellular, tissue, and system levels. In: Riegel, R.J. and Godbold, J.C.Jr., editors. Laser Therapy in Veterinary Medicine. $1^{\text {st }}$ ed. John Wiley \& Son, Inc., Ames, IA. p36-51.

9. Karu, T. (2010) Mitochondrial mechanisms of photobiomodulation in context of new data about multiple roles of ATP. Photomed. Laser Surg., 28(2): 159-160.

10. Huang, Y.Y., Sharma, S.K., Carroll, J. and Hamblin, M.R. (2011) Biphasic dose response in low level light therapy-an update. Dose Response, 9(4): 602-618.

11. Kilík, R., Lakyová, L., Sabo, J., Kruzliak, P., Lacjaková, K., Vasilenko, T., Vidová, M., Longauer, F. and Radoňak, J. (2014) Effect of equal daily doses achieved by different power densities of low-level laser therapy at $635 \mathrm{~nm}$ on open skin wound healing in normal and diabetic rats. Biomed. Res. Int., 2014: 269253.

12. de Castro, J.R., da Silva Pereira, F., Chen, L., AranaChavez, V.E., Ballester, R.Y., DiPietro, L.A. and Simões, A. (2020) Improvement of full-thickness rat skin wounds by photobiomodulation therapy (PBMT): A dosimetric study. J. Photochem. Photobiol. B., 206: 111850.

13. Posten, W., Wrone, D.A., Dover, J.S., Arndt, K.A., Silapunt, S. and Alam, M. (2005) Low-level laser therapy for wound healing: Mechanism and efficacy. Dermatol. Surg., 31(3): 334-340.

14. Wang, Z.X. and Kim, S.H. (2020) Effect of photobiomodulation therapy $(660 \mathrm{~nm})$ on wound healing of rat skin infected by Staphylococcus. Photobiomodul. Photomed. Laser Surg., 38(7): 419-424.

15. Ghamsari, S.M., Yamada, H., Acorda, J.A. and Unno, N. (1994) Evaluation of low level laser therapy on open wound healing of the teat in dairy cattle. Laser Ther., 6: 113-118.

16. Wardlaw, J.L., Gazzola, K.M., Wagoner, A., Brinkman, E., Burt, J., Butler, R., Gunter, J.M. and Senter, L.H. (2018) Laser therapy for incision healing in 9 dogs. Front. Vet. Sci., 5(349): 00349

17. Kurach, L.M., Stanley, B.J., Gazzola, K.M., Fritz, M.C., Steficek, B.A., Hauptman, J.G. and Seymour, K.J. (2015) The effect of low-level laser therapy on the healing of open wounds in dogs. Vet. Surg., 44(8): 988-996.

18. Gammel, J.E., Biskup, J.J., Drum, M.G., Newkirk, K. and Lux, C.N. (2018) Effects of low-level laser therapy on the healing of surgically closed incisions and surgically created open wounds in dogs. Vet. Surg., 47(4): 499-506.

19. Archibald, K.E., Harrison, T., Troan, B., Smith, D. and Minter, L.J. (2020) Effect of multiradiance low-level laser therapy and topical silver sulfadiazine on healing characteristics of dermal wounds in marine toads (Rhinella marina). Vet. Med. Int., 2020: 8888328.

20. Luna, S.P.L., Schoen, A., Trindade, P.H.E. and da Rocha, P.B. (2020) Penetration profiles of a class IV therapeutic laser and a photobiomodulation therapy device in equine skin. J. Equine Vet. Sci., 85: 102846.

21. Yadav, A., Gupta, A., Keshri, G.K., Verma, S., Sharma, S.K. and Singh, S.B. (2016) Photobiomodulatory effects of superpulsed $904 \mathrm{~nm}$ laser therapy on bioenergetics status in burn wound healing. J. Photochem. Photobiol. B., 162: 77-85

22. Moriyama, Y., Nguyen, J., Akens, M., Moriyama, E.H. and Lilge, L. (2009) In vivo effects of low level laser therapy on inducible nitric oxide synthase. Lasers Surg. Med., 41(3): 227-231.

23. Chow, S., Wang, H. and Shao, J. (2007) Sample Size Calculations in Clinical Research. $2^{\text {nd }}$ ed. Chapman \& Hall/ CRC, Boca Raton, USA. p480.

24. Sanati, M.H., Torkaman, G., Hedayati, M. and Dizaji, M.M. (2011) Effect of Ga-As (904nm) and He-Ne (632.8 nm) laser on injury potential of skin full-thickness wound. J. Photochem. Photobiol. B., 103(2): 180-185.

25. Millis, D.L. and Saunders, D.G. (2014) Laser therapy in canine rehabilitation. In: Millis, D.L. and Levine, D., editors. Canine Rehabilitation and Physical Therapy. $2^{\text {nd }}$ ed. W.B. Saunders, St. Louis. p359-380.

26. Kampa, N., Jitpean, S., Seesupa, S. and Hoisang, S. (2020) Penetration depth study of $830 \mathrm{~nm}$ low-intensity laser therapy on living dog tissue. Vet. World, 13(7): 1417-1422.

27. Harris, C., Bates-Jensen, B., Parslow, N., Raizman, R., Singh, M. and Ketchen, R. (2010) Bates-Jensen wound assessment tool. J. Wound Ostomy Cont., 37(3): 253-259.

28. Lucroy, M.D., Edwards, B.F. and Madewell, B.R. (1999) Low-intensity laser light-induced closure of a chronic wound in a dog. Vet. Surg., 28(4): 292-295.

29. Wu, X., Alberico, S., Saidu, E., Khan, S.R., Zheng, S., Romero, R., Chae, H.S., Li, S., Mochizuki, A. and Anders, J. (2015) Organic light emitting diode improves diabetic cutaneous wound healing in rats. Wound Repair. Regen., 23(1): 104-114.

30. Barbosa, L.S., Parisi, J.R., Viana, L.C., Carneiro, M.B., Novaes, R.D. and de Sousa, L. (2020) The photobiomodulation $(658,830$ and $904 \mathrm{~nm})$ on wound healing in histomorphometric analysis. Fisioter. Mov., 33: e003318.

31. Munap, D.H.F., Lau, P.S., Bidin, N., Bakhtiar, H. and Krishnan, G. (2019) Effects of photobiomodulation therapy with various laser power densities on wound healing. J. Phys. Conf. Ser., 1151: 012011.

32. Rathnakar, B., Rao, B.S., Prabhu, V., Chandra, S., Rai S., Rao, A.C., Sharma, M., Gupta, P.K. and Mahato, K.K. (2016) Photo-biomodulatory response of low-power laser irradiation on burn tissue repair in mice. Lasers Med. Sci., 31(9): 1741-1750.

33. Mao, Z., Wu, J.H., Dong, T. and Wu, M.X. (2016) Additive enhancement of wound healing in diabetic mice by low level light and topical CoQ10. Sci. Rep., 6: 20084.

34. Lagan, K.M., Mc Donough, S.M., Clements, B.A. and Baxter, G.D. (2000) A case report of low intensity laser therapy (LILT) in the management of venous ulceration: Potential effects of wound debridement upon efficacy. J. Clin. Laser Med. Surg., 18(1): 15-22.

35. Lee, S.Y.C., Seong, I.W., Kim, J.S., Cheon, K.A., Gu, S.H., Kim, H.H. and Park, K.H. (2011) Enhancement of cutaneous immune response to bacterial infection after low-level light therapy with $1072 \mathrm{~nm}$ infrared light: A preliminary study. J. Photochem. Photobiol. B., 105(3): 175-182.

36. de Loura Santana, C., de Fátima Teixeira Silva, D., de Souza, A.P., Jacinto, M.V., Bussadori, S.K., MesquitaFerrari, R.A., Fernandes, K.P. and França, C.M. (2016) Effect of laser therapy on immune cells infiltrate after excisional wounds in diabetic rats. Lasers Surg. Med., 48(1): 
45-51.

37. Stadler, I., Lanzafame, R.J., Evans, R., Narayan, V., Dailey, B., Buehner, N. and Naim, J.O. (2001) 830-nm irradiation increases the wound tensile strength in a diabetic murine model. Lasers Surg. Med., 28(3): 220-226.

38. Mendez, T.M.T., Pinheiro, A.L.B., Pacheco, M.T.T., Nascimento, P.M. and Ramalho, L.M.P. (2004) Dose and wavelength of laser light have influence on the repair of cutaneous wounds. J. Clin. Laser Med. Surg., 22(1): 19-25.

39. Rezende, S.B., Ribeiro, M.S., Núñez, S.C., Garcia, V.G. and Maldonado, E.P. (2007) Effects of a single near-infrared laser treatment on cutaneous wound healing: Biometrical and histological study in rats. J. Photochem. Photobiol. B., 87(3): 145-153.

40. Michanek, P., Toth, T., Bergström, E., TreffenbergPettersson, H. and Bergh, A. (2020) Effect of infrared and red monochromatic light on equine wound healing. Equine Vet. J., 53(1): 143-148.

41. Minatel, D.G., Frade, M.A., França, S.C. and Enwemeka, C.S. (2009) Phototherapy promotes healing of chronic diabetic leg ulcers that failed to respond to other therapies. Lasers Surg. Med., 41(6): 433-441.

42. Santos, N.R.S., Sobrinho, J.B.M., Almeida, P.F., Ribeiro, A.A., Cangussú, M.C.T., dos Santos, J.N. and Pinheiro, A.L. (2011) Influence of the combination of infrared and red laser light on the healing of cutaneous wounds infected by Staphylococcus aureus. Photomed. Laser Surg., 29(3): 177-182.

43. Rodrigo, S.M., Cunha, A., Pozza, D.H., Blaya, D.S.,
Moraes, J.F., Weber, J.B.B. and de Oliveira, M.G. (2009) Analysis of the systemic effect of red and infrared laser therapy on wound repair. Photomed. Laser. Surg., 27(6): 929-935.

44. Figurová, M., Ledecký, V., Karasová, M., Hluchý, M., Trbolova, A., Capík, I., Hornak, S., Reichel, P., Bjordal, J.M. and Gál, P. (2016) Histological assessment of a combined low-level laser/light-emitting diode therapy $(685 \mathrm{~nm} / 470 \mathrm{~nm})$ for sutured skin incisions in a porcine model: A short report. Photomed. Laser. Surg., 34(2): 1-3.

45. Lima, A.M.C., da Silva Sergio, L.P. and de Souza da Fonseca, A. (2020) Photobiomodulation via multiple-wavelength radiations. Lasers Med. Sci., 35(2): 307-316.

46. Bordvik, D., Sturla, H., Naterstad, I.N., Lopes-Martins, R., Leal Junior, E., Bjordal, J. and Joensen, J. (2017) Penetration time profiles for two class 3B lasers in in situ human achilles at rest and stretched. Photomed. Laser. Surg., 35(10): 546-554.

47. Volk, S.W. and Bohling, M.W. (2013) Comparative wound healing-are the small animal veterinarian's clinical patients an improved translational model for human wound healing research? Wound Repair Regen., 21(3): 372-381.

48. Masson-Meyers, D.S., Andrade, T.A.M., Caetano, G.F., Guimaraes, F.R., Leite, M.N., Leite, S.N. and Frade, M.A.C. (2020) Experimental models and methods for cutaneous wound healing assessment. Int. J. Exp. Pathol., 101(1-2): 21-37.

49. Chang, A., Dearman, B. and Greenwood, J.E. (2011) A comparison of wound area measurement techniques: Visitrak versus photography. Eplasty, 11(18): 158-166. 